\title{
Analisa Perancangan Model Sistem Monitoring, Pencatatan Dan Pengiriman Hasil Produksi Truk Dengan Remote File Transfer System (RFTS) Pada Perusahaan XYZ Menggunakan Metode System Development Life Cycle
}

\author{
Sigit Wijayanto ${ }^{1}$ \\ Universitas Bakrie \\ Jl. HR Rasuna Said Kav C-22, Kuningan, Jakarta Selatan \\ Corresponding author's e-mail: sigit.wijayanto@bakrie.ac.id
}

\begin{abstract}
Abstrak - Sebuah perusahaan otomotif internasional yang bernama XYZ Indonesia, mengalami sebuah masalah pelayanan purna jual dalam penjualan truk yang mereka lakukan di Indonesia. Masalah tersebut terjadi ketika pelanggan mengajukan servis gratis dari truk yang sudah mereka beli. Salah satu syarat pengajuan adalah mesin dan casis masih seperti saat pelanggan tersebut membelinya. Hal ini menjadi sebuah masalah, karena manajemen di Indonesia tidak memiliki dokumentasi yang baik terkait kegiatan penggabungan casis dan mesin oleh XYZ Indonesia. Untuk diketaui bahwa casis truk memang diproduksi di Indonesia, tetapi mesin truk didatangkan langsung dari India, hal ini dikarenakan XYZ India merupakan sentralisasi pembuatan mesin truk untuk kawasan Asia tenggara. Oleh sebab itu, pembuatan sebuah sistem baru yang mampu mengakomodir pencatatan kegiatan penggabungan casis dan mesin yang dilakukan oleh XYZ Indonesia, dirasa penting. Tujuan dari penelitian ini adalah mampu memberikan saran kepada pihak $\mathrm{XYZ}$ Indonesia.
\end{abstract}

Kata kunci: RFTS, Casis, Mesin, Nomor Identifikasi Truk

\section{Pendahuluan}

Perkembangan sistem informasi memiliki dampak yang cukup besar pada kehidupan saat ini. Pertukaran informasi ke berbagai penjuru dunia saat ini bisa terjadi dalam hitungan detik saja. Hal ini berdampak kepada organisasi untuk melakukan perencanaan terkait sistem informasi ini yang bersifat strategis. Robbin dan Coulter [1] menyatakan, bahwa perencanaan meliputi hal pendefinisian sasaran organisasi, penetapan strategi menyeluruh untuk mencapai sasaran itu, dan penyusunan serangkaian rencana yang menyeluruh untuk mengintegrasikan dan mengkoordinasikan pekerjaan organisasi.

Keuntungan yang sama pun telah dirasakan oleh berbagai perusahaan internasional, yang telah meggunakan sistem pertukaran pesan jarak jauh. Mereka mampu menggunakan teknologi informasi untuk mencapai tingkat efisiensi kerja yang cukup tinggi, sehingga mampu mendapatkan data atau pesan yang paling aktual secara cepat. Selain itu, beberapa keuntungan lainnya adalah [2]:

a. Mengurangi penggunaan kertas antar organisasi

b. Meningkatkan produktivitas

c. Memungkinkan penyaluran informasi yang lebih efisien

d. Mempercepat pengiriman informasi antar organisasi

e. Meningkatkan akurasi informasi dan mengurangi kesalahan

f. Membuka kesempatan untuk mendapatkan keuntungan dari setiap teknologi baru

Seperti halnya di perusahaan internasional lainnya, perusahaan XYZ yang bergerak di bidang otomotif, juga telah menggunakan teknologi informasi untuk berbagai macam kegiatan bisnis mereka. [3] Seperti pengawasan terhadap perpindahan barang di logistik, serta di bagian marketing, sales dan layanan purna jual. Tetapi, masih terdapat berbagai masalah yang dialami oleh perusahaan XYZ, dalam hal pengolahan data di dalam divisi layanan purna jual truk.Di dalam salah satu klausa pengajuan servis gratis yang diatur oleh perusahaan XYZ Indonesia, terdapat poin yang menjelaskan bahwa nomor identifikasi (TIN-Truck Identification Number), nomor mesin (TEN-Truck Engine Number) dan nomor casis (TCN-Truck Chassis Number) yang dimiliki oleh truk harus sama seperti pada saat perakitan. Hal ini bisa diidentifikasi secara mudah, karena hasil perakitan tersebut, akan menghasilkan 1 nomor TIN (Truck Identification Number). Ini menjadi persyaratan penting saat pengajuan servis gratis, karena apabila nomor mesin atau nomor casis dari truk yang diajukan sudah tidak sesuai dengan yang tertera di dalam informasi TIN, maka pihak XYZ Indonesia berhak menolak pengajuan servis gratis.

Berkaitan dengan hal tersebut, di internal XYZ Indonesia juga memiliki masalah manajemen informasi. Dimana terdapat banyak kesalahan yang mengakibatkan mereka tidak memiliki informasi terkait TIN, TEN dan TCN. Masalah tersebut juga berimbas terhadap pihak XYZ India yang harus mendokumentasikan nomor mesin yang telah digabung dengan nomor casis.

Lebih lanjut lagi, masalah tersebut akhirnya diketahui oleh pihak XYZ pusat, yang berlokasi di Polandia. 
Mereka ingin mengetahui bagaimana masalah tersebut akan diselesaikan. Selain itu , mereka juga meminta agar mereka dikirimkan informasi nomor casis (TCN) yang diproduksi oleh XYZ Indonesia, serta hasil penggabungan mesin dan casis truk (TIN) ini setiap kali ada produksi. Hal ini seperti ditulis oleh Magal, S.R. dan Word, J [4], bahwa dalam level agregasi, sebuah entreprise system dapat membantu perusahaan mengevaluasi seberapa baik sebuah proses procurement dilaksanakan berdasarkan oleh kalkulasi "lead time", atau berapa lama waktu yang dibutuhkan dari sebuah pengiriman hingga sampai ke penerima. Data tersebut akan menunjukan bagaimana proses tersebut berjalan. Karena apabila terjadi hambatan, akan terlihat ada kelebihan dari ambang waktu wajar.

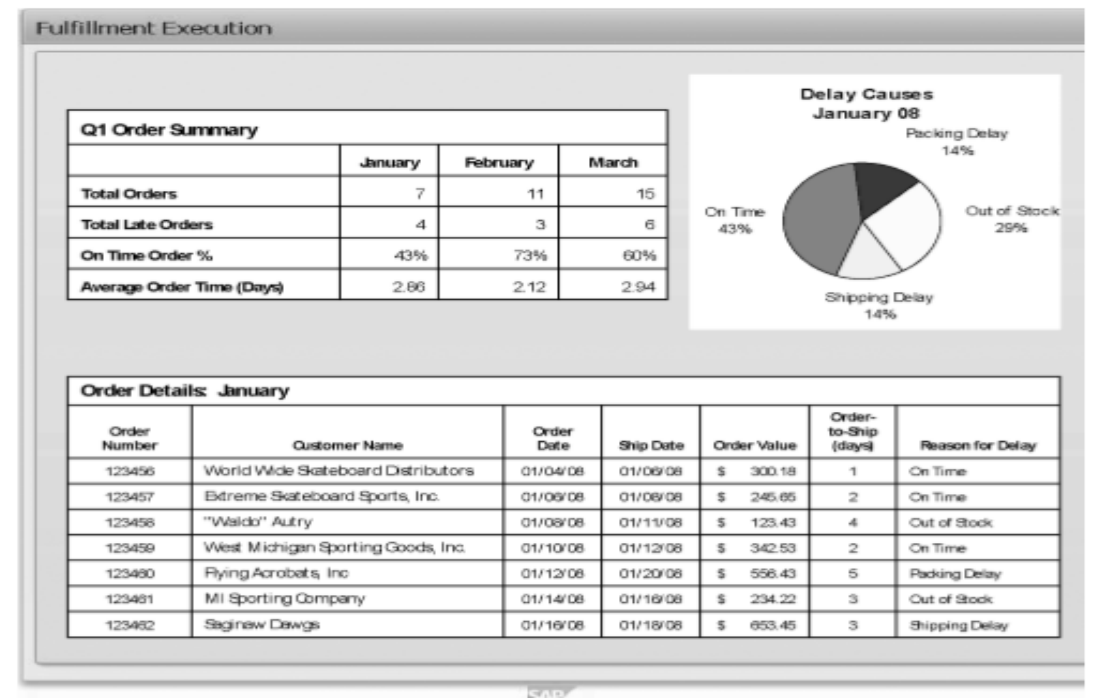

Gambar 1 Contoh process-level information

Sumber: Copyright SAP AG 2008 [4]

Oleh karena itu, untuk mengefisiensikan perekaman dan pertukaran data yang terjadi, pihak XYZ indonesia memutuskan untuk membuat sebuah sistem yang dinamakan ECParts. Sistem ECParts ini sendiri diharapkan akan mampu mengatasi permasalahan pertukaran data tersebut, yang nantinya akan mengirimkan data-data tersebut ke negara india dan polandia.

\section{Metode Penelitian}

Penelitian ini menggunakan konsep metode kualitatif yang bertujuan untuk menganalisis aktivitas yang terjadi di dalam lingkup perusahaan XYZ Indonesia, India dan Polandia. Serta penulis juga menggunakan metode System Development Life Cycle (SDLC) untuk menganalisa kebutuhan dan merancang keluaran sistem dalam perusahaan XYZ.

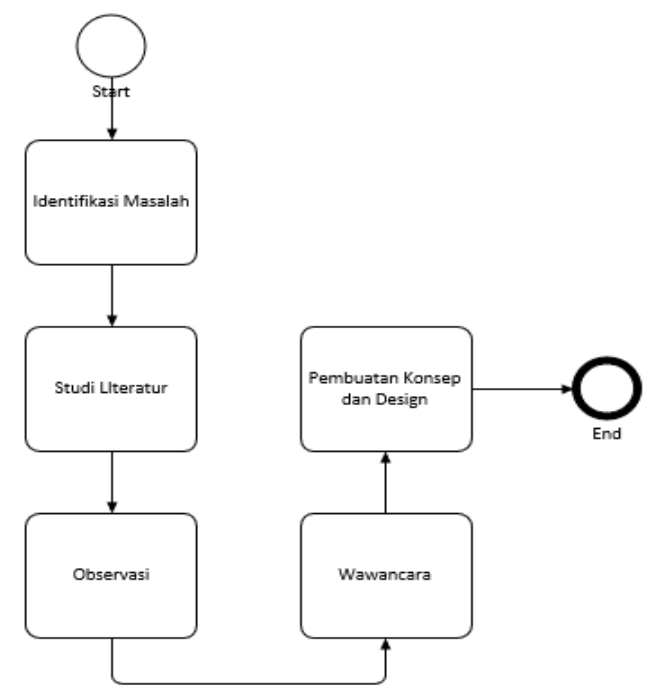

Gambar 2 Kerangka Penelitian 
Dalam penelitian ini penulis melakukan beberapa tahapan. Tahap pertama, penulis akan mengidentifikasi masalah dan membuat rumusan serta ruang lingkup masalah. Tahap kedua, mengumpulkan beberapa referensi berupa jurnal, buku dan website internal perusahaan XYZ Indonesia. Tahap berikutnya adalah observasi dan wawancara. Penulis akan mendatangi lokasi perusahaan XYZ Indonesia, guna melihat langsung bagaimana standard operational procedure (SOP) dan workflow dari sistem yang sedang berjalan saat ini[10]. Karena menurut Riadi, M [5], SOP dapat digunakan untuk menjaga konsistensi tingkat penampilan kinerja atau kondisi tertentu dan bagaimana petugas dalam melaksanakan sesuatu tugas atau pekerjaan tertentu. Hal ini dianggap penulis perlu dilakukan karena akan berdampak kepada tingkat kesalahan yanag dilakukan oleh karyawan yang bertugas terkait produksi truk.Tahap ketiga yang akan dilakukan oleh penulis adalah wawancara. Wawancara ini akan melibatkan 12 karyawan XYZ dari ketiga negara. Komposisi karyawan yang akan diwawancara adalah:

Tabel 1 Demografi sasaran wawancara terkait ECParts

\begin{tabular}{|c|c|c|c|c|c|c|}
\hline No & $\begin{array}{l}\text { Lokasi Karyawan } \\
\text { Perusahaan XYZ }\end{array}$ & Departemen & Umur & $\begin{array}{l}\text { Latar } \\
\text { Belakang } \\
\text { pendidikan }\end{array}$ & Jabatan & $\begin{array}{l}\text { Pengalaman } \\
\text { Kerja }\end{array}$ \\
\hline 1 & \multirow{8}{*}{ Indonesia } & \multirow{2}{*}{ Pergudangan } & 45 tahun & $\mathrm{S} 1$ & Manajer & 22 tahun \\
\hline 2 & & & 49 tahun & S1 & Staf & 27 tahun \\
\hline 3 & & \multirow{2}{*}{ Logistik } & 55 tahun & S2 & Manajer & 30 tahun \\
\hline 4 & & & 29 tahun & S1 & Staf & 5 tahun \\
\hline 5 & & \multirow{2}{*}{ Produksi } & 48 tahun & S1 & Manajer & 26 tahun \\
\hline 6 & & & 35 tahun & D3 & Staf & 15 tahun \\
\hline 7 & & \multirow{6}{*}{$\begin{array}{l}\text { Teknologi } \\
\text { Informasi }\end{array}$} & 24 tahun & S1 & $\begin{array}{l}\text { Kepala } \\
\text { Proyek }\end{array}$ & 3 tahun \\
\hline 8 & & & 35 tahun & S1 & Staff & 23 tahun \\
\hline 9 & \multirow{2}{*}{ India } & & 38 tahun & $\mathrm{S} 2$ & Manajer & 10 tahun \\
\hline 10 & & & 30 tahun & S1 & Staf & 9 tahun \\
\hline 11 & \multirow{2}{*}{ Polandia } & & 33 tahun & S2 & Manajer & 5 tahun \\
\hline 12 & & & 28 tahun & $\mathrm{S} 2$ & Staf & 3 tahun \\
\hline
\end{tabular}

Penulis mewawancarai 6 orang karyawan dari departemen logistik, produksi dan pergudangan di XYZ Indonesia, yang menjadi pengguna dari sistem TIN yang telah berjalan selama ini. Selain itu, 2 orang karyawan dari Teknologi Informasi juga dilibatkan, karena departemen mereka akan dibebankan tugas menjadi administrator dari sistem baru yang akan dijalankan dari pihak XYZ Indonesia. Jabatan-jabatan yang dipegang karyawan tersebut adalah manajer dan staf. Hal ini agar penulis dapat memiliki pandangan dari skala manajerial dan staf. Lalu secara garis besar, penulis akan menanyakan bagaimana kebutuhan perangkat lunak maupun perangkat keras yang dibutuhkan oleh sistem baru tersebut.

Selanjutnya, untuk proses wawancara dengan 4 orang karyawan departemen Teknologi Informasi dari India dan Polandia, dilakukan dengan menggunakan tele-, videoconference. Dengan ke 4 orang karyawan tersebut, penulis akan menanyakan beberapa hal terkait infrastruktur teknologi informasi yang ada di XYZ India dan Polandia, yang nantinya akan digunakan untuk keperluan sistem yang baru ini.

Hasil dari pengumpulan data yang penulis lakukan adalah dibuatnya sebuah workflow sebagai desain konsep protokol sistem. Berikut adalah desain konsep protokol sistem untuk ECParts. 


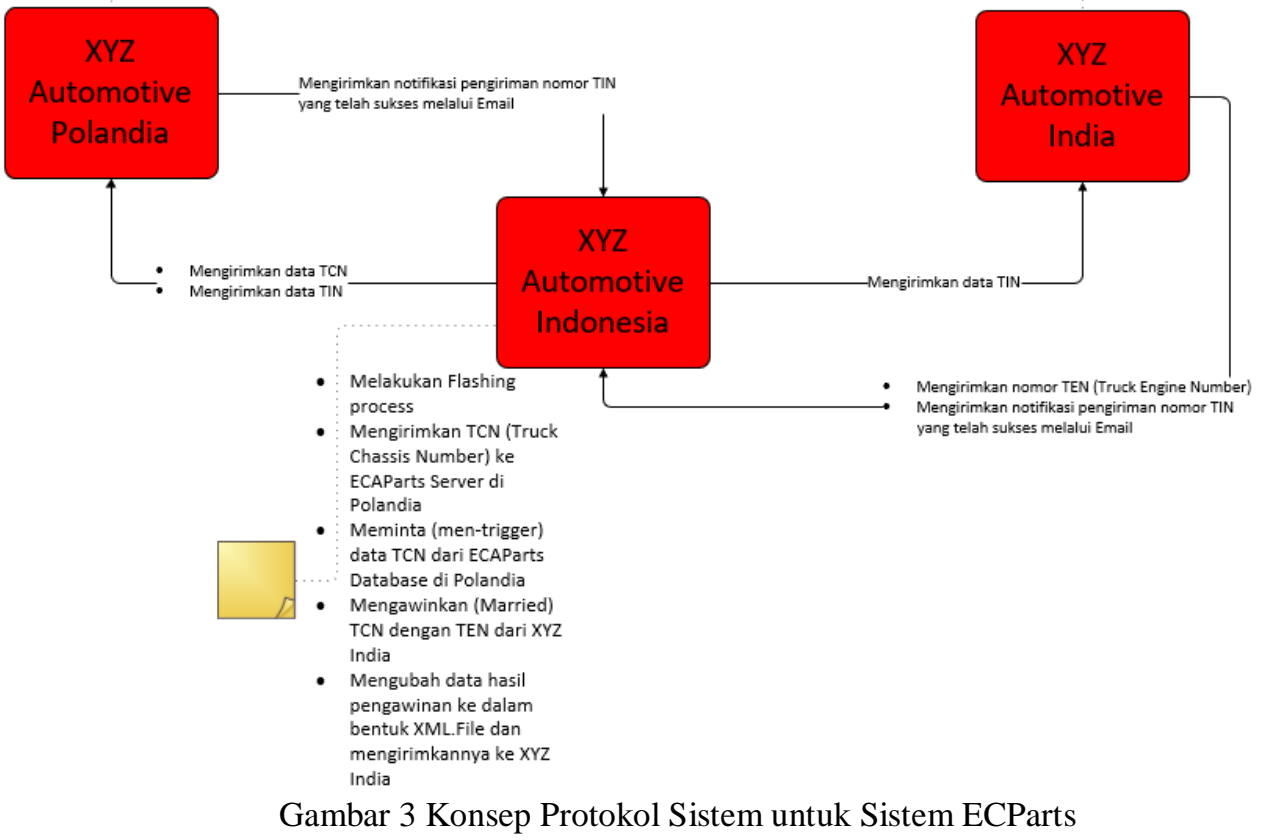

Dalam konsep protokol sistem ini, dapat dijelaskan bahwa proses yang pertama kali dijalankan adalah pengiriman nomor TEN dari XYZ India. Selanjutnya, XYZ Indonesia akan menggabungkan casis (TCN) yang diproduksi di XYZ Indonesia dan mesin (TEN) yang diproduksi di XYZ India. Setelah itu, hasil penggabungan tersebut akan menghasilkan 1 nomor TIN (Truck Identification Number) yang akan dikirimkan kepada XYZ Polandia dan XYZ India lengkap dengan nomor TCN dan TEN yang terkandung di dalam informasi nomor TIN. Selain mengirimkan nomor TIN secara berkala kepada pihak XYZ Polandia dan India, XYZ Indonesia juga dapat mengirimkan informasi TCN yang diproduksi oleh mereka kepada XYZ Polandia. Selanjutnya, proses terakhir yang akan dilakukan adalah pengiriman notifikasi kepada XYZ Indonesia dari XYZ Polandia ataupun XYZ India, apakah pengiriman data tersebut telah berhasil atau tidak. Apabila pengiriman data tersebut tidak berhasil, maka pihak XYZ Indonesia akan mengirimkan ulang secara manual Informasi TIN tersebut.

\section{Spesifikasi Sistem}

\subsection{Parameter Data}

Data nomor casis (TCN) dan mesin (TEN) yang telah digabungkan, akan menghasilkan nomor TIN Nomor TIN ini yang nantinya akan dikirimkan ke ECParts server dan database yang berada di Polandia dan ECParts database2 di XYZ India. Selain itu pengiriman data TCN dari XYZ Indonesia juga akan menggunakan metode yang sama, dimana pengiriman akan dilakukan setelah data dirubah kedalam format XML

3.2. Spesifikasi General untuk System Interface

Tabel 2 Demografi sasaran wawancara terkait ECParts

\begin{tabular}{|l|l|l|}
\hline A: Export Service & Name & $\begin{array}{l}\text { ECPARTS_INDONESIA_PARAMETE } \\
\text { RS_DDMMYYYYHHMMSS.XML }\end{array}$ \\
\hline & Version & 1.0 .0 .0 \\
\hline B: ECParts Server & Name & \\
\hline $\begin{array}{l}\text { Previously valid } \\
\text { interface specification }\end{array}$ & Version & \\
\hline & Vame & \\
\hline
\end{tabular}




\begin{tabular}{|l|l|l|}
\hline $\begin{array}{l}\text { New interface } \\
\text { specification }\end{array}$ & Name & Indonesia Interface \\
\hline & Version & 0.4 - Topic 2 \\
\hline
\end{tabular}

\subsection{Input Parameter}

Berikut adalah beberapa parameter terpilih yang termasuk dalam XML input parameter:

Tabel 3 Demografi sasaran wawancara terkait ECParts

\begin{tabular}{|c|c|c|c|c|c|c|}
\hline $\begin{array}{l}\text { XML filed } \\
\text { name }\end{array}$ & Description & $\begin{array}{c}\text { TKU } \\
\text { Description }\end{array}$ & $\begin{array}{l}\text { resolution } \\
\text { [/Bit] }\end{array}$ & Value range & Type & PID \\
\hline Engine number & $\begin{array}{l}\text { parameterized } \\
\text { engine number }\end{array}$ & $\begin{array}{l}\text { Engine } \\
\text { number }\end{array}$ & $\mathrm{x}$ & $\mathrm{x}$ & Varchar & 14 \\
\hline Idcode & Engine idcode & $\begin{array}{l}\text { Selected ID- } \\
\text { Code }\end{array}$ & $\mathrm{x}$ & $\mathrm{x}$ & Varchar & \\
\hline ROT1 & Rotation 1 & X Rotation 1 & $0.19 \mathrm{~min}-1$ & $0 . .8000 \mathrm{~min}-1$ & Int & 15 \\
\hline ROT2 & Rotation 2 & X Rotation 2 & 0.19 min- 1 & $0 . .8000 \mathrm{~min}-1$ & Int & 15 \\
\hline $\mathrm{AJ} 1$ & Adjust 1 & AJ-1 & $1.0=8265$ & $0 . .3,0$ & float & 19 \\
\hline $\mathrm{AJ} 2$ & Adjust 2 & AJ-2 & $1.0=8265$ & $0 . .3,0$ & float & 19 \\
\hline PARAMETER1 & Parameter 1 & $\begin{array}{c}\text { Vehicle } \\
\text { parameter } \\
\text { level } 1\end{array}$ & 1 & & int & 64 \\
\hline PARAMETER2 & Parameter 2 & $\begin{array}{l}\text { Vehicle } \\
\text { parameter } \\
\text { level } 2\end{array}$ & 1 & & int & 64 \\
\hline Tll1 & Temperature & $\begin{array}{c}\text { Temperature } \\
\text { level } 1\end{array}$ & $1{ }^{\circ} \mathrm{C}$ & $0 . .180{ }^{\circ} \mathrm{C}$ & int & 75 \\
\hline Tl12 & Temperature & $\begin{array}{c}\text { Temperature } \\
\text { level } 2\end{array}$ & $1{ }^{\circ} \mathrm{C}$ & $0 . .180{ }^{\circ} \mathrm{C}$ & int & 75 \\
\hline
\end{tabular}

\subsection{Input XML}

Format data XML harus sesuai ketentuan sebagai berikut:

1. Format nama:

\section{ECPARTS_INDONESIA_PARAMETERS_DDMMYYYY_HHMMSS.XML}

2. Semua atribut yang diklasifikasikan penting harus dideklarasikan, bahkan ketika tidak memiliki nilai (nol).

3. Data XML harus disandikan sesuai dengan UTF-8.

4. Desimal harus dipisahkan dengan titik (.)

5. Dikirim dengan id = "001". Misalnya <PARAME-TERS = "001">

6. Nomor ID harus selalu dengan kutipan. Contoh $\langle$ PARAMETERS id = "002">

7. Penomoran id dapat diatur ulang untuk setiap data XML.

8. Format tanggal harus YYYY-MM-DD HH: MM: SS.000.

\subsection{Error Handling}

1. Jika XML dalam format yang salah, sistem akan memberikan pemberitahuan kepada pengirim. Jika belum ada tanggapan setelah pemberitahuan, maka data yang tidak valid akan dihapus.

2. Jika ada bidang "bukan nol (not null)" ditemukan di XML, sistem akan mengasumsikan nilai 0 . Contoh <PARAMETER5></ PARAMETER5>. Nilai PARAMETER5 adalah 0.

3.6. External Constraints

1. Operator sistem harus mengirim e-mail status dan penyebab error kepada tim ECParts jika menemukan error pada sistem.

2. Komunikasi antara ECPartsUpdater dan server FTP Polandia dilakukan melalui TCP / IP.

3. Interface Protocol: FTP 
4. Interchange files format: XML

5. Safety: Pertukaran file akan dilakukan sepenuhnya oleh jaringan perusahaan XYZ.

6. Setiap proses pertukaran informasi akan dimulai setelah adanya permintaan koneksi akses dan akan terputus setelah pekerjaan selesai. Tidak diperbolehkan untuk membiarkan koneksi tetap terbuka setelah proses pertukaran data.

7. Jika ada masalah koneksi dengan FTP, sistem akan melaporkannya melalui e-mail dan sistem akan berhenti secara otomatis. Setelah masalah koneksi selesai, operator diminta untuk memulai pengkoneksian kembali pada proses berikutnya.

8. Sistem akan menginformasikan LOG melalui email, ketika sistem dimulai, status sistem sedang berjalan dan proses telah selesai. Email ini akan dikirim ke administrator sistem ECParts.

9. Penyimpanan dalam database akan dilakukan dalam urutan atribut "id" dari kecil ke besar.

10. Jika ada lebih dari satu file XML yang akan diproses memiliki "id" yang sama, maka penyimpanan akan dilakukan sesuai dengan urutan tanggal yang diidentifikasi oleh DDMMYYYYY_HHMMSS dalam nama file XML.

11. File XML harus selalu mengikuti format yang dicontohkan. Huruf demi huruf dan koma desimal (,) atau format waktu "YYYY-MM-DD HH: MM: SS.000". Apabila ditemukan kesalahn, data tersebut akan ditolak.

12. ECPartsUpdater akan beroperasi satu kali dalam setiap periode / sekali dalam setiap 1 (satu) jam.

\section{Hasil dan Pembahasan}

4.1. Proses penginputan dan pengiriman data TCN ke XYZ Polandia

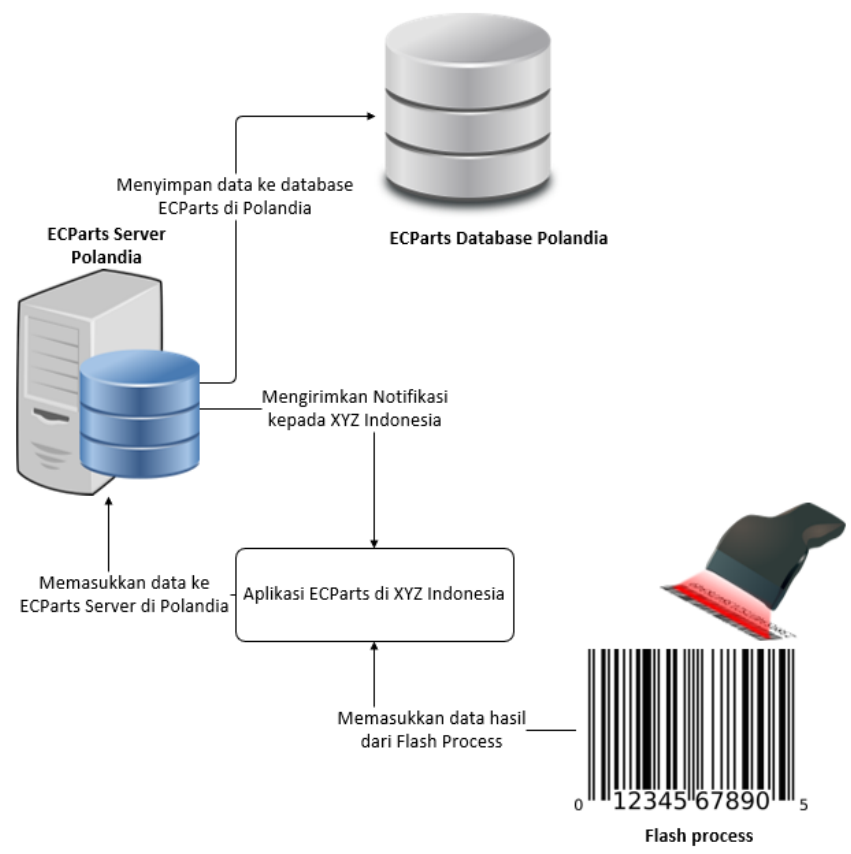

Gambar 4 Contoh process-level information

Pengumpulan data dimulai dari proses flash pada nomor casis yang dilakukan XYZ Indonesia. Data yang diperoleh dari proses ini adalah data TCN (Truck Chassis Number) dari produksi casis truk. Seperti yang dijelaskan pada gambar di atas, setelah flash proses selesai dilakukan, data akan dimasukkan ke dalam aplikasi ECParts Indonesia, disini data akan dirubah kedalam bentuk XML untuk kemudian dikirim ke server ECParts di Polandia. Selanjutnya, notifikasi akan dikirimkan ke pihak XYZ Indonesia. Apabila data telah terkirim dengan baik, notifikasi tersebut akan di rekam sebagai bagian dari laporan pengiriman. Namun apabila pengiriman pertama gagal, maka notifikasi ini akan menginformasikan aplikasi ECParts dan administrator di Indonesia agar melakukan pencarian alasan kenapa kegagalan pengiriman data, memperbaiki masalah tersebut dan melakukan pengiriman ulang. Terakhir, Data yang telah berhasil diterima oleh server ECParts di Polandia, akan disimpan di database ECParts Polandia. Disini data bisa diakses oleh semua perusahaan XYZ di dunia yang memiliki akses dan kebutuhan terhadap data tersebut.

\subsection{Proses Pengiriman Data TIN}

Proses pengiriman data TIN akan dilakukan setelah dihasilkannya nomor tersebut dalam proses 
penggabungan casis dan mesin di XYZ Indonesia. Kemudian data dirubah kedalam bentuk XML. Selanjutnya, data tersebut akan dikirimkan kepada ECParts server dan database di Polandia. Selain itu, ECParts Indonesia juga melakukan pengiriman data TIN kepada XYZ India. Sesuai permintaan manajemen, yang didapatkan dari proses wawancara, seluruh pengiriman data harus menggunakan metode yang memiliki standar keamanan tinggi dalam hal pertukaran data dan informasi. Dalam hal ini, manajemen perusahaan XYZ juga meminta untuk menggunakan product Remote File Transfer Service (RFTS), yang sudah digunakan di perusahaan XYZ untuk kebutuhan pengiriman data ke perusahaan XYZ di seluruh dunia maupun internal perusahaan di dalam satu negara.

RFTS sendiri adalah aplikasi transfer file yang dimiliki oleh Owl Cyber Defense, yang mengelola pengiriman file dalam Cloud Computing dan lingkungan mesin virtual yang memungkinkan banyak pengguna akhir untuk mengirimkan file tunggal, beberapa data atau 1 direktori sekaligus dengan menggunakan File Transfer Protocol (FTP) dan Network File System (NFS). Selain itu, RFTS juga dapat melakukan enkripsi, pindai dan menyaring data sebelum dipindahkan. [6]

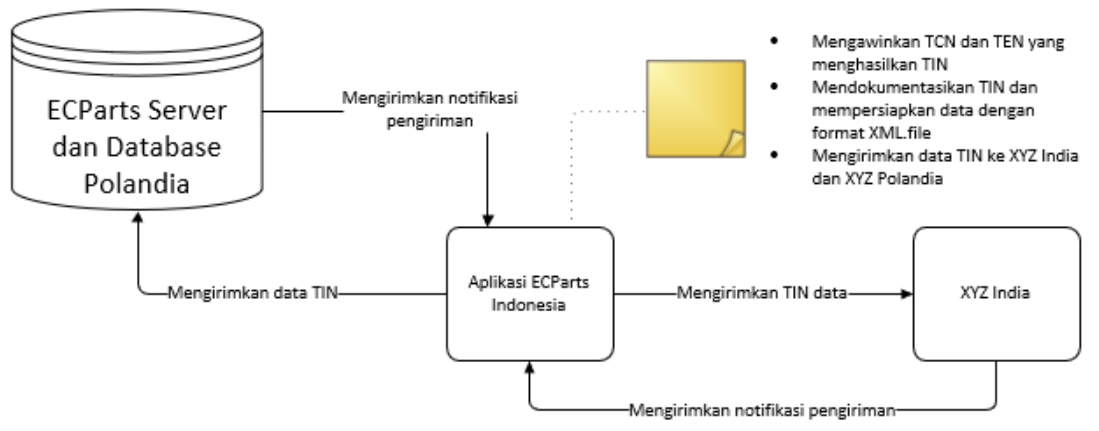

Gambar 5 Contoh process-level information

Seperti proses pengiriman data lainnya dalam aplikasi ECParts ini, setelah dilakukan pengiriman, server penerima akan mengirimkan notifikasi kepada server pengirim dengan menggunakan E-Mail. Baik pengiriman itu gagal ataupun berhasil. Salah satu contoh pengiriman gagal adalah, ketika data XML yang dikirim itu sampai, isi dari data XML tersebut corrupt. Dikarenakan terjadi kesalahan dalam perubahan jenis data ke dalam bentul XML

\subsection{Diskusi}

Pada studi ini, penulis menggunakan metode penelitian kualitatif yang telah digunakan pada penelitian terdahulu, yakni penelitian yang dilakukan oleh Alfarisy dan Diana [7] Dimana pada penelitian tersebut dikembangkan sebuah sistem informasi yang memiliki sistem penjadwalan dalam penyewaan mobil, serta pembuatan database yang mampu menampung data dalam jumlah besar, yang nantinya dapat dimanfaatkan untuk pembuatan berbagai macam laporan yang dibutuhkan secara internal. Hal ini didasari oleh analisa yang telah dilakukan kedua peneliti untuk mengetahui kebutuhan pengguna dengan menggunakan metode System Development Life Cycle (SDLC) dan pembuatan database berbasis MySql. Tujuan penggunaan SDLC dan MySql disini agar apabila dikemudian hari perusahaan membutuhkan sistem baru, akan mempermudah kegiatan pembaruan tersebut.

Kemudian pada penelitian ini, variable constraint utama adalah perbedaan waktu untuk mendapatkan informasi dari perusahaan yang berdomisili di 3 negara yang berbeda. Namun pendekatan ini dirasa penulis yang terbaik, karena data yang didapatkan akan lebih sesuai dengan kebutuhan penggunan. Teknologi RFID (Radio Frequency Identification) pada penelitian Neforawati, Fareza dan Juniarti [8], menjadi pembanding dengan teknologi RFTS yang digunakan penulis dalam penelitian ini. Memang dapat kita buktikan bahwa teknologi RFID dapat digunakan tanpa membutuhkan paket data, sesuai temuan dari Neforawati, Fareza dan Juniarti (2015) yang mengungkap fakta bahwa pengunaan komunikasi jaringan pada sistem transfer data pada teknologi RFID berjalan dengan baik tanpa adanya paket data yang hilang. Pengujian data random 100 dan 200 data pada 10 sample didapatkan hasil delay 0.622 , packet loss 0 , dan jitter sebersar 0.0157 yang berarti sistem perancangan dapat digunakan sangat baik berdasarkan standar. Penelitian selanjutnya terkait pembuatan aplikasi android dan aplikasi web menyimpulkan bahwa pembuatan sistem informasi absensi dengan menggunakan NFC telah di implementasikan dan dapat dipergunakan dengan baik. Tetapi teknologi RFID belum mampu digunakan untuk pengiriman data jaarak jauh dan dari segi keamanannya dirasa penulis masih belum cukup baik apabila diimplementasikan kepada perusahaan XYZ Indonesia yang membutuhkan transmisi antar benua.

Begitu pula dengan teknologi NFC yang digunakan pada pembuatan sistem informasi absensi yang 
dilakukan oleh Fajriyani, Pujiharsoono dan Arifin [9]. Karena dengan lokasi yang berbeda benua, tidak mungkin menggunakan teknologi NFC. Hal ini dikarenakan, teknologi near field communication (NFC) mengharuskan device pengguna bersentuhan dengan device penerima yang biasanya ditempelkan pada suatu tempat..

\section{Kesimpulan}

Di dalam kajian ini, disampaikan analisa sistem permodelan ECParts yang dibuat berdasarkan hasil dari pengumpulan data yang dilakukan oleh penulis. Sistem permodelan tersebut akan dapat menjawab masalah seperti berikut ini:

1. Hasil penggabungan mesin (Truck Engine Number (TEN)), yang didapatkan dari mesin yang diimpor dari India, dengan casis (Truck Chassis Number (TCN)), yang didapatkan dari casis yang diproduksi oleh XYZ Indonesia, akan menghasilkan Truck Identification Number (TIN). Nomor TIN ini nantinya akan dikirimkan kepada XYZ pusat di Polandia dan XYZ India secara otomatis melalui sistem ECParts.

2. Pendokumentasian proses ini juga dapat menjawab tantangan yang diberikan oleh XYZ pusat yang berlokasi di Polandia. Dimana mereka meminta pendokumentasian nomor TCN dan TIN dikirimkan juga ke ECParts server dan database di Polandia, agar XYZ pusat dapat memonitor setiap produksi truk di indonesia dan penyimpanannya dapat diatur dengan lebih baik.

\section{Daftar Pustaka}

Format daftar pustaka ditulis dengan format IEEE.

[1] Robbins, S.P. ; Coulter, M.,(2004). Management, (Alih Bahasa T. Hernaya,dan Harry Slamet, Jilid I, Edisi ketujuh. Jakarta)

[2] Scala, S; McGrath Jr., R(1993). Research Advantages and disadvantages of electronic data interchange; An industry perspective. 0378-7206/93/\$06.00 1993 - Elsevier Science Publishers B.V. All rights reserved.

[3] XYZ Indonesia (2019).

[4] Simha R. Magal, Word. J, p. cm. (1993). Essentials of business processes and information systems ISBN 978-0-470-23059-6 (pbk.).

[5] Riadi, M.,(2016). Pengertian, Tujuan, Fungsi dan Manfaat SOP. https://www.kajianpustaka.com/2016/10/pengertian-tujuan-fungsi-dan-manfaat-sop.html (diakses pada tanggal 11 september 2019)

[6] Owl Cyber Defense (2019) Remote File Transfer Service (RFTS) (https://owlcyberdefense.com/data-diode-products/commercial-products/software-modules/rfts/) (diakses pada tanggal 20 September 2019)

[7] Alfarisy, M.H.; Diana, A. (201--). Rancang Bangun Sistem Informasi Penyewaan Mobil pada Abu Sulaiman Rent Car.

(http://teknik.univpancasila.ac.id/semrestek/prosiding/index.php/12345/article/view/244/228), Jurnal Poli-Teknologi, Politeknik Negeri Jakarta.

[8] Neforawati, I.; Fareza, M.I.; Juniarti, V. (2015). Rancang Bangung Aplikasi Sistem Informasi Monitoring Absensi Mahasiswa Politeknik Negeri Jakarta Menggunakan Teknologi NFC pada Android. (http://jurnal.pnj.ac.id/index.php/politeknologi/article/view/740/452), Jurnal PoliTeknologi, Politeknik Negeri Jakarta.

[9] Fajriyani, L.A.; Pujiharsoono, H. ; Arifin, J. (2018). Perancangan dan Analisa Sistem Rekam Medis Rumah Sakit Berbasis Wireless Menggunakan Teknologi RFID Sebagai Identitas (http://conferences.ittelkom-pwt.ac.id/index.php/centive/article/view/46/46), IT Telkom Purwokerto.

[10]D. Satria, Zulfan, Munawir, and T. Hidayat, "Implementation of wireless sensor network (WSN) on garbage transport warning information system using GSM module," J. Phys. Conf. Ser., vol. 1175, p. 12054, 2019. 